\title{
A ADOÇÃO DE UM CURRÍCULO INTERDISCIPLINAR NA EDUCAÇÃO E NO ESTUDO DAS CULTURAS ERUDITAS E POPULARES NO CONTEXTO BRASILEIRO
}

\section{THE ADOPTION OF AN INTERDISCIPLINARY SYLLABUS IN EDUCATION AND IN THE STUDY OF THE ERUDITE AND POPULAR CULTURES IN THE BRAZILIAN CONTEXT}

\author{
Sonia Regina Albano de Lima \\ Universidade Estadual Paulista "Júlio de Mesquita Filho" \\ soniaalbano@uol.com.br
}

\section{Resumo}

- texto que se segue analisa as duas concepções de interdisciplinaridade - a concepção a-histórica e a concepção histórico dialética, tanto nas ciências como na educação. Sob essa perspectiva serão avaliados os currículos interdisciplinares com o intuito de minimizar a fragmentação epistemológica instaurada após o cartesianismo. Nesse sentido gestores da educação devem apresentar propostas curriculares interdisciplinares focadas em três dimensões epistemológicas de forma integrada - dimensão ética, cultural e social. Os relatos aqui produzidos estão fundamentados basicamente nos escritos de M. F. Gomes da Silva (2009) e A. C. Lopes e E. Macedo (org) (2005). O texto culmina com a análise de E. Fubini, entre outros musicólogos, apontando o isolamento epistemológico presente na produção musical contemporânea, o que corrobora um fazer musical fragmentado e hiperespecializado, na contramão de um padrão cultural híbrido instaurado na sociedade contemporânea.

Palavras-chave: interdisciplinaridade; concepção a-histórica; concepção histórico-dialética; currículo interdisciplinar; produção musical. 


\begin{abstract}
The present text analyses the two conceptions of interdisciplinarity - the a-historical conception and the dialectic historical conception, both in the sciences and in education. Under this perspective, the interdisciplinary syllabuses will be assessed with the purpose of minimizing the epistemological fragmentation that was established after the Cartesianism. In this sense, in an integrated way, the education supervisors must present interdisciplinary syllabus proposals focused on three epistemological dimensions - the ethical, cultural and social dimensions. The reports hereby produced are basically founded in the works of $M$. F. Comes da Silva (2009) and A. C. Lopes and E. Macedo (org) (2005). The text culminates with the analysis of E. Fubini, among other musicologists, pointing out the epistemological isolation present in the contemporary musical production, which confirms a fragmented and hyper-specialized musical practice, in the opposite way of a hybrid cultural pattern set up in the contemporary society.
\end{abstract}

Keywords: interdisciplinarity; a-historical conception; historicaldialectical conception; interdisciplinary syllabus; musical production.

\title{
Introdução
}

Na epistemologia contemporânea a adoção de procedimentos interdisciplinares tem se tornado cada vez mais oportuna, considerandose a fragmentação cognitiva instaurada nos diversos campos de conhecimento e a diversidade de problemas sociopolíticos que afligem o mundo contemporâneo. Tanto nas ciências como na educação, a ação interdisciplinar é capaz de realizar transformações sociais importantes, mudar as relações de poder instauradas, rechaçar saberes cristalizados que já não são benéficos nem para os individuos nem para a sociedade. No que se reporta à educação, a adoção da interdisciplinaridade por parte dos gestores, coordenadores e professores tem se concentrado na construção de parcerias com organismos públicos e privados, no intuito de melhor servir a sociedade, integrar a Educação ao todo social e promover a integração dialética do sujeito com o mundo subjetivo e objetivo, construindo um conhecimento que prioriza uma perspectiva de ação humanista e político-social. 
A especialização imposta às diversas áreas de conhecimento tem, cada vez mais, afastado os individuos de uma compreensão holística do universo, promovendo um tipo de saber que aos poucos se esgota nele mesmo. Esta compreensão holística do universo esteve bem presente na Antiga Crécia (século VI a.C). Os gregos antigos pensavam o mundo como uma unidade; todo o conhecimento era praticado no seu todo holístico, apresentando traços característicos de uma cultura global. Como retratado por Comes da Silva (2009, p. 44), neste período o conhecimento assumiu contornos de um todo indiscriminado; contudo, a partir do século XVI, o conhecimento começa a se fragmentar, centrado na ideia de que questões complexas deveriam ser resolvidas por partes e não sob uma perspectiva globalizante. Esse racionalismo cartesiano disseminou ao longo dos anos a ideia de um mundo mecanicista, similar a uma máquina, amparado em preceitos matemáticos, cujas explicações estruturais e funcionais processavam-se sob uma perspectiva de decomposição do todo em partes. A visão de um mundo fragmentado, a compartimentalização da existência, a perda da unidade universal, fez surgir uma ciência multiplicada em diversos ramos, cada uma seguindo um caminho diferente. Na Educação essa fragmentação propagou-se na criação de cursos concentrados em áreas de saber específicas com matrizes curriculares voltadas a atender uma única realidade cognitiva:

Do ponto de vista epistemológico, a fragmentação dos saberes em disciplinas tem como marca o primado da razão, herança do Renascimento radicalizado no lluminismo Europeu e, a partir do século XVIII, acentuada com o desenvolvimento técnico e científico das sociedades europeias modernas [...] a racionalidade disciplinar corresponde principalmente a um processo de subjetivação atrelado às estruturas de poder e à lógica do controle da qual a instituição escolar compartilha. As disciplinas não seriam, portanto, conhecimentos neutros, mas mecanismos de regulação da conduta e formas de exercício de poder. Por isso, se a educação é uma prática disciplinar de normalização e controle social, é desta maneira que se constitui a subjetividade dos sujeitos pedagógicos (lbid, 45-46).

Esse prognóstico propagou-se para o interior dos sistemas educacionais, disseminando um ensino que gradativamente impediu professores e alunos de participarem dos processos de reflexão crítica 
da realidade social. Nessa modalidade de ensino a construção de conhecimento não está atravessada pela problematização ou por atitudes de indagação, eixos norteadores de uma prática pedagógica interdisciplinar.

\title{
O século XX e a adoção do pensamento interdisciplinar
}

Foi a partir do século XX, no intuito de minimizar a fragmentação epistemológica instaurada, que o pensamento interdisciplinar começou a ser utilizado com maior frequência tanto nas ciências como na Educação, não com o intuito de abolir uma perspectiva de análise disciplinar, mas como forma de alimentá-la, considerando-se que na interdisciplinaridade há maior intensidade de trocas entre os estudiosos, maior integração de disciplinas, mais diálogo e interação de áreas (LENOIR 1998, p. 46). Este pensamento entra em ação na hora de enfrentar os problemas e as questões que surgem em cada sociedade e de certa maneira traz de volta a forma de pensar dos Antigos Gregos. Comes da Silva ao traçar um breve histórico do movimento em prol da implantação crescente da interdisciplinaridade relata:

\begin{abstract}
[...] pode-se dizer que o movimento da interdisciplinaridade na sociedade actual é algo que deverá afirmar-se com toda a força por meio de mudanças sociais profundas que não se localizem apenas no plano escolar, mas que promovam reflexões consubstanciais em espaços sociais problemáticos, onde a construção de todo e qualquer conhecimento seja feita pela crítica permanente do sujeito sobre o objecto, de modo que a pessoa possa enfrentar os problemas da sociedade actual tendo como base um conhecimento científico numa perspectiva mais crítica (COMES DA SILVA,2009, p. 7 I)
\end{abstract}

Da parte dos educadores a função de transmitir a cultura objetivada, o cuidado com o desenvolvimento da personalidade global dos sujeitos, a preparação para o trabalho e a universalização dos bens culturais, tem exigido o repasse de um ensino interdisciplinar: 
[...] a atribuição destas funções à escola parece querer atribuir-lhe a tarefa de integração harmoniosa dos sujeitos através da educação, a fim de que estes pudessem colaborar para o progresso das sociedades na direção do ideal democrático [...]. Essa necessidade de superação da fragmentação do conhecimento justifica-se, pelo menos a princípio, pela compreensão crítica da importância da interacção e transformação recíprocas entre diferentes áreas de saber (lbid, p. 74)

Nesse sentido, as pesquisas centradas na análise e reformulação curricular têm se intensificado com o objetivo de construir um pensamento educacional que não seja a somatória de conteúdos e disciplinas informacionais, desvinculado dos problemas complexos que afligem o mundo como um todo, mesmo se considerarmos que a organização curricular atual ainda está alicerçada em torno de disciplinas estanques, sem interconexão, fato que impede a aquisição de um conhecimento integrado e complexo.

pensamento interdisciplinar quando empregado na Educação pode substituir a concepção fragmentária de pensamento por uma concepção unitária e complexa do ser humano que perpassa o âmbito escolar, fazendo com que as ações decorrentes do currículo escolar se realizem dentro de um tecido social complexo capaz de pensar as relações sociais como relações políticas. Pensada como um sistema de colaboração entre diversas disciplinas ou entre setores heterogêneos de uma mesma ciência, a interdisciplinaridade leva seus participantes a reconhecer os limites dos seus saberes para acolher as contribuições de outras disciplinas. Dessa maneira, uma ciência ou uma disciplina, tornase complemento de outra e converge para atingir objetivos mútuos (COMES DA SILVA, 2009).

Na atualidade as discussões envolvendo questões curriculares têm sido bastante discutidas na Educação e no intuito de construir um currículo escolar mais democrático a interdisciplinaridade tem se tornado um referencial importante a ser adotado.

Sob uma perspectiva racionalista, hoje o currículo ainda é tratado como um conjunto de saberes transmitidos e organizados pela escola ou, como um conjunto de matérias a serem ensinadas. Nesse sentido ele privilegia, em grande parte, a repetição, a memorização

\section{4}


de conhecimentos que se petrificam ao longo dos tempos, sem estabelecer conexão com os conflitos sociais vividos pelo sujeito no âmbito das relações sociais. $\bigcirc$ que importa é a transmissão de um saber compartimentalizado com base em um plano organizado em torno das disciplinas e de conteúdos considerados clássicos. Estes são ensinados pelos professores sob um crivo hierárquico onde o conhecimento que eles propagam não são colocados em xeque, e, da parte do corpo discente há a aceitação plena do conteúdo repassado sob uma perspectiva deveras alienante (ibid, p. 28). Nesse modelo curricular não há possibilidades de se interagir de forma interdisciplinar.

No intuito de trabalhar conteúdos curriculares sob uma perspectiva interdisciplinar, Gomes da Silva (2009), expõe duas concepções de integração curricular consolidadas na interdisciplinaridade, tendo como objetivo essencial construir uma escola mais democrática a luz da contemporaneidade: a concepção a-histórica e a concepção histórico-dialética.

A primeira concepção (a-histórica) caracteriza-se por privilegiar mais intensamente a ação do sujeito sobre o objeto. Nestes casos, o sujeito é absoluto na construção do conhecimento e do pensamento, contudo, na concepção histórico-dialética também são colocadas em discussão as condições objetivas que envolvem o processo de construção do conhecimento. Embora as duas concepções atuem sob uma perspectiva interdisciplinar, é na segunda corrente que se concentra mais diretamente a materialização de uma formação curricular efetivamente democrática, já que essa perspectiva pressupõe a inclusão de aspectos alusivos à integração, à parceira, à totalidade histórica, à mediação, aos conflitos sociais e às atitudes que os sujeitos necessitam adquirir no processo de aquisição do conhecimento (ibid, p. 95).

Em contrapartida, o enfoque curricular tecnicista que ainda é utilizado nas escolas, tem bem mais presente a habilitação do indivíduo para exercer uma única profissão e não consideram as questões de ordem social que envolvem os sujeitos. Como relata Comes da Silva, pautado nos relatos de Leite', o enfoque curricular tecnicista tem como preocupação a preparação dos sujeitos para uma profissão sob a égide da divisão/fragmentação e exploração social do trabalho:

I Conforme expresso em LEITE, Carlinda. O Currículo e o Multiculturalismo no Sistema Educativo Português. Fundação Calouste Gulbenkian, 2002.

\section{5}


Nessa visão curricular há uma racionalidade instrumental que ignora questões de ordem ética e ideológica e não tem em conta a complexidade e diversidade das situações inerentes aos processos educativos e normalizadores, pois esquece os contextos e as características dos formadores, os princípios que orientam o currículo e os processos do seu desenvolvimento, bem como valores e opções que o informam e enformam (COMES DA SILVA, 2009, p. 100).

De acordo com esta autora, na disciplinarização do conhecimento está embutido de maneira subjetiva uma organização sociocultural que também é fragmentada, onde cada disciplina representa um território conquistado pelos diferentes professores que atuam de forma isolada, e que, desta forma, formam cada vez mais fortes a reprodução das relações sociais de exploração.

Gomes da Silva vê na concepção curricular histórico-dialética a possibilidade que as ações educativas possam se estender para além dos muros escolares, como um instrumento capaz de captar a problemática social e a sua realidade. Nesse caso a escola não assume sozinha a função de educar, mas atua em parceria com outras instituições e com a comunidade. Desenvolve-se, nesse caso, parcerias onde se discute como estão acontecendo ou aconteceram a produção da existência humana. Nessa concepção interdisciplinar o currículo é pensado como um conjunto de experiências de aprendizagem focando a teoria e a prática de maneira conjunta e a produção do conhecimento é encarada como um problema histórico-cultural com profundo senso epistemológico. Aqui a interdisciplinaridade não se propaga como uma somatória dos sujeitos pensantes que, de acordo com suas vontades, supera o problema da fragmentação do conhecimento e transforma as desigualdades sociais, como acontece na corrente a-histórica. $\mathrm{Na}$ concepção histórico-dialética presume-se que o sujeito só será capaz de intervir no processo de transformação social, se no decurso de uma reorganização curricular a parceria que se estabelece interage na construção de uma sociedade integralmente educada.

Na atualidade, cada vez mais é exigido da Educação que as disciplinas sejam trabalhadas de forma integrada, independentemente de as instituições partilharem de uma ou outra concepção curricular acima relatada, o que faz desaparecer gradativamente as fronteiras entre as disciplinas, tornando o currículo mais significativo. Há nessa

\section{6}

REV. TULHA, RIBEIRÃO PRETO, v. 6, n. 2, pp. 90- 1 18, jul.-dez. 2020 
integração, fatores exógenos que decorrem das formas como a escola se organiza, do modelo de organização curricular que adota e das condições socioculturais e do ambiente familiar onde os alunos são socializados. Nesse sentido a construção curricular cada vez mais tem se preocupado em integrar e discutir questões socioculturais e permitir que os atores envolvidos nessa construção possam interagir de forma democrática. Nesse sentido o professor e as instituições adquirem a tarefa de reformular padrões educativos cristalizados, implantar novos padrões e atender mais prontamente os interesses socioculturais que acercam o ambiente escolar; de outra parte, os alunos podem a partir deste comportamento, escolher as ações e os conteúdos que the permitam atuar na sociedade de forma mais enfática, assim professor, aluno e instituições de ensino estabelecem uma parceira não hierarquizada.

Gomes da Silva relata que pensar um currículo interdisciplinar não é pensar em um processo de acumulação ou justaposição de disciplinas, como algo neutro e não atravessado pelos conflitos de ordem social, tarefas mais presentes nas ações educativas de cunho pluri e multidisciplinar. Ações educativas na formação dos currículos focadas na multidisciplinaridade caracterizam-se pela justaposição de matérias diferentes, oferecidas de maneira simultânea, com a intenção de esclarecer alguns de seus elementos comuns, mas, na verdade não explicitam de forma clara, as possíveis relações estabelecidas entre elas. Por sua vez, as ações educativas pluridisciplinares justapõem disciplinas mais ou menos próximas dentro do mesmo setor de conhecimentos (ibid, p. 49-50).

Mesmo se considerarmos essas duas ações diferentes e mais promissoras do que as ações disciplinares que permeiam a educação e embutem no seu âmago uma postura de força, onde a possibilidade de comunicação torna-se desequilibrada, já que uma disciplina pode concentrar uma relação hierárquica mais profunda em relação as demais, elas também se diferenciam de uma ação educativa interdisciplinar, principalmente quando essas ações estão focadas em uma concepção interdisciplinar histórico-dialética. Sob essa concepção as ações interdisciplinares permitem a abertura de novos caminhos para a Educação, para a Sociedade e para a Cultura de um país, podendo até mesmo influenciar o padrão epistemológico adotado nas ciências naturais e sociais, no sentido de revalorizar mais intensamente os caminhos da humanidade como um todo (ibid, 116). 


\title{
Os atores do ensino atuando em uma perspectiva curricular interdisciplinar
}

Para que se adote na educação uma perspectiva curricular interdisciplinar tanto os alunos como os professores devem ser reeducadores, de forma a melhor trabalhar na escola as necessidades atinentes ao século atual. Deve ser superada a racionalidade científica instaurada durante o positivismo e cuidar de remodelar o currículo escolar, trazendo para a educação novos paradigmas epistemológicos e socioculturais. Para isso é necessário que se estabeleça um processo de comunicação entre as várias disciplinas, que enfatize mais intensamente a pluralidade dos saberes por meio de ações interligadas; deve-se superar a visão restrita dos currículos da atualidade; buscar flexibilizar cada vez mais a matriz curricular dos cursos e enfrentar a hiperespecialização presente na educação atual. $\mathrm{Na}$ atualidade é importante ao professor e às instituições, agregar ao ensino, os fenômenos sociais de ordem diversa, capazes de conduzir o homem a uma melhor posição social e profissional. Conforme expressa Comes da Silva:

\begin{abstract}
[...] práticas desse tipo exigem de todos os gestores do currículo e, em particular dos professores, o domínio do conhecimento numa perspectiva multidimensional. De facto, para que os professores actuem como agentes intervenientes de currículos interdisciplinares há que enfrentar o problema que a hiperespecialização do conhecimento acarreta, em termos dos currículos escolares e que, segundo Morin (2001:13) impede de ver o global (que ela fragmenta em parcelas), bem como o essencial (que ela dilui) (COMES DA SILVA, 2009, p. 122).
\end{abstract}

Pode-se afirmar que os professores nessa relação integrada, enquanto representantes legítimos de currículos interdisciplinares, deverão dar conta das articulações entre domínios das disciplinas que são quebrados pelo pensamento disjuntivo. Há, portanto, a necessidade que o professor adquira uma nova postura epistemológica que leve em conta a complexidade do pensamento humano, um pensamento que não separa, mas une, buscando as relações necessárias e interdependentes de todos os aspectos da vida humana e a construção do conhecimento. 
Não obstante a reciprocidade cognitiva que ele deve estabelecer com os alunos é importante.

Essa nova modalidade de pensamento vem acompanhado de incertezas, pois considera a diversidade, a incompatibilidade nas ideias parceiras, as crenças e percepções dos atores envolvidos no processo que devem ser cotidianamente discutidas. Como relata Comes da Silva, de acordo com o que profetiza E. Morin², é importante nos dias atuais que o professor e os demais gestores da Educação tenham a consciência de que o ser humano transita sobre um universo de complexidades $e$, como tal, não é mais possivel adotar um currículo que separa o que está ligado, decompõe sem recompor e recorta o pensamento do aluno causando-lhe verdadeiras desordens e contradições no que diz respeito ao entendimento que este deverá ter sobre o objeto cognoscente. Para essa autora é muito difícil separar a ideia de organização curricular da ideia de um pensamento complexo relatado por E. Morin.

Sob esse entendimento, uma proposta curricular interdisciplinar pressupõe a atenção dos gestores da educação focadas em três dimensões epistemológicas atuando de forma interligada: a dimensão ética, a dimensão cultural e a social. Na dimensão ética, o sujeito social é um ser capaz de se auto organizar e de estabelecer relações com o outro, transformando-se continuamente, dentro desta ótica. Na dimensão cultural o homem se realiza pela cultura e na cultura, portanto, não há cultura sem cérebro humano. A mente humana é uma criação que emerge e se afirma na relação cérebro-cultura e deve levar em conta o alargamento máximo que remete a totalidade do conhecimento em diferentes espaços e tempos pelos diversos atores do processo educativo. Na dimensão social é preciso que o currículo questione a relação entre a definição do ensino com a estrutura do poder da sociedade. Sob esta dimensão o estudioso da política curricular deve estar atento ao contexto e aos condicionamentos de natureza social impostos em estreita e contínua relação com a sua dimensão cultural e ética.

posicionamento desta autora retrata que, embora seja cada vez mais referendada na Educação a inserção de um pensamento curricular interdisciplinar, ele ainda está longe de existir de forma plena,

2 Pensamento extraído do livro A cabeça bem-feita: repensar a reforma. Reformar o pensamento de E. Morin. Rio de Janeiro: Bertrand Brasil, 2001. 
pois exigiria da parte das políticas públicas e das instituições de ensino uma reformulação completa na maneira de agir de seus gestores. $\bigcirc$ mais corriqueiro que se tem presenciado é o agir coletivo por parte de alguns coordenadores, professores e mesmo da instituição como um todo, como uma equipe, no sentido de trabalhar uma ou mais disciplinas sob uma perspectiva integrativa, o que enfatiza mais de perto estar havendo um trabalho pluridisciplinar, descontextualizado de uma ação dialógica envolvida com a problemática social. Nesse sentido ainda prevalece a fragmentação do conhecimento.

Temos aqui a adoção de um pensamento interdisciplinar onde a própria história dos sujeitos não está presente no processo de análise. Como nos diz Comes da Silva, trata-se de uma forma simples de interdisciplinaridade, presente na concepção a-histórica, que envolve a somatória de individualidades ou de sujeitos pensantes que não apreende a complexidade do problema, objeto de análise. Nesta concepção não se mexe em estruturas sociais e políticas de poder. Ela desconsidera a problemática de caráter social, político e econômico, subjacentes às políticas de globalização que excluem milhares de cidadãos do processo de construção de um conhecimento crítico, interdisciplinar e mais complexo. Nessa concepção a interdisciplinaridade na Educação deveria se impor como uma necessidade histórico-cultural e epistemológica conforme expresso na concepção histórico-dialética. Aqui a interdisciplinaridade se impõe enquanto deliberação coletiva de problemas públicos, para repensar, redescobrir e reconceitualizar a realidade social de forma a atender mais intensamente os interesses das classes hegemônicas que conduzem a sociedade. Trata-se de um caminho de contínuas incertezas e ambiguidades pois, nesses casos, o conhecimento está sempre a se construir e desconstruir (ibid, 90-92).

Essa fala de Comes da Silva nos faz pensar que ainda, por bons anos vamos trabalhar com uma concepção de interdisciplinaridade a-histórica, voltada mais incisivamente a propagar uma programação curricular que atinge mais diretamente contextos pluri e multidisciplinares ou formações isoladas de alguns professores, gestores ou instituições de ensino que assim se predispõe a trabalhar. A concretização de uma interdisciplinaridade histórico-dialética exigiria uma mudança radical do pensamento humano e das políticas governamentais atuais, o que modificaria substancialmente o pensamento humano e a sociedade de modo geral. Como as mudanças epistemológicas necessitam de longos anos para serem superadas ou modificadas, a adoção 
de uma concepção curricular a-histórica parece-nos uma solução plausivel momentaneamente, que poderá se modificar ao longo dos anos, difundindo uma proposta educativa mais voltada aos interesses socioculturais.

É nessa direção mais restrita que a política educacional brasileira tem se conduzido. Os ordenamentos voltados para Educação no Brasil têm adotado uma ação e padrão interdisciplinar curricular bem mais voltado para a concepção a-histórica. A BNCC, homologada em 20 de dezembro de 2017 pelo Ministro da Educação Mendonça Filho, é um desses exemplos. Trata-se de um documento de caráter normativo que define o conjunto orgânico e progressivo de aprendizagens essenciais que todos os alunos devem desenvolver ao longo das etapas e modalidades da Educação Básica, de modo a que tenham assegurados seus direitos de aprendizagem e desenvolvimento, em conformidade com o que preceitua o Plano Nacional de Educação (PNE). Este documento normativo aplica-se exclusivamente à educação escolar, acompanhando as determinações relatadas na LDB n. 9394/96 e presume estar embasada em princípios éticos, políticos e estéticos que visam a formação humana integral e a construção de uma sociedade justa, democrática e inclusiva, como fundamentado nas Diretrizes Curriculares Nacionais da Educação Básica (BRASIL, BNCC, p. 7).

A leitura deste ordenamento e das competências a ele determinadas, faz pensar que ele adota um pensamento educacional adequado a concepção curricular interdisciplinar histórico-dialógica propagada por Comes da Silva, contudo o próprio Ministro da Educação Rossieli Soares da Silva, na apresentação desse ordenamento, põe em xeque essa ideia ao afirmar:

A BNCC por si só não alterará o quadro de desigualdade ainda presente na Educação Básica do Brasil, mas é essencial para que a mudança tenha início porque, além dos currículos, influenciará a formação inicial e continuada dos educadores, a produção de materiais didáticos, as matrizes de avaliações e os exames nacionais que serão revistos à luz do texto homologado da Base. Temos um documento relevante, pautado em altas expectativas de aprendizagem, que deve ser acompanhado pela sociedade para que, em regime de colaboração, faça - país avançar. Assim como aconteceu na etapa já

\section{1}

REV. TULHA, RIBEIRÃO PRETO, v. 6, n. 2, pp. 90- 118 , jul.-dez. 2020 
homologada, a BNCC passa agora às redes de ensino, às escolas e aos educadores. Cabe ao MEC ser um grande parceiro neste processo, de modo que, em regime de colaboração, as mudanças esperadas alcancem cada sala de aula das escolas brasileiras. Somente aí teremos cumprido o compromisso da equidade que a sociedade brasileira espera daqueles que juntos atuam na educação (BRASIL, BNCC, p. 5).

Considerado uma referência nacional para a formulação dos currículos dos sistemas e das redes escolares dos Estados, do Distrito Federal e dos Municípios e das propostas pedagógicas das instituições escolares, a BNCC integra a política nacional da Educação Básica e deve contribuir para o alinhamento de outras políticas e ações, em âmbito federal, estadual e municipal, referentes à formação de professores, à avaliação, à elaboração de conteúdos educacionais e aos critérios para a oferta de uma infraestrutura adequada para o pleno desenvolvimento da educação. Nesse sentido, espera-se que ele ajude a superar a fragmentação das políticas educacionais, enseje o fortalecimento do regime de colaboração entre as três esferas de governo e seja balizador da qualidade da educação. Para tanto traz 10 competências gerais para a educação básica que se bem observadas, reafirmam uma ação pedagógica interdisciplinar similar a concepção curricular histórico-dialógica, assim relatadas:

1. Valorizar e utilizar os conhecimentos historicamente construídos sobre o mundo físico, social, cultural e digital para entender e explicar a realidade, continuar aprendendo e colaborar para a construção de uma sociedade justa, democrática e inclusiva.

2. Exercitar a curiosidade intelectual e recorrer à abordagem própria das ciências, incluindo a investigação, a reflexão, a análise crítica, a imaginação e a criatividade, para investigar causas, elaborar e testar hipóteses, formular e resolver problemas e criar soluções (inclusive tecnológicas) com base nos conhecimentos das diferentes áreas.

3. Valorizar e fruir as diversas manifestações artísticas e culturais, das locais às mundiais, e também participar de práticas diversificadas da produção artístico-cultural.

\section{2}

REV. TULHA, RIBEIRÃO PRETO, v. 6, n. 2, pp. 90- 11 , jul.-dez. 2020 
4. Utilizar diferentes linguagens - verbal (oral ou visualmotora, como Libras, e escrita), corporal, visual, sonora e digital-, bem como conhecimentos das linguagens artística, matemática e científica, para se expressar e partilhar informações, experiências, ideias e sentimentos em diferentes contextos e produzir sentidos que levem ao entendimento mútuo.

5. Compreender, utilizar e criar tecnologias digitais de informação e comunicação de forma crítica, significativa, reflexiva e ética nas diversas práticas sociais (incluindo as escolares) para se comunicar, acessar e disseminar informações, produzir conhecimentos, resolver problemas e exercer protagonismo e autoria na vida pessoal e coletiva.

6. Valorizar a diversidade de saberes e vivências culturais e apropriar-se de conhecimentos e experiências que the possibilitem entender as relações próprias do mundo do trabalho e fazer escolhas alinhadas ao exercício da cidadania e ao seu projeto de vida, com liberdade, autonomia, consciência crítica e responsabilidade.

7. Argumentar com base em fatos, dados e informações confiáveis, para formular, negociar e defender ideias, pontos de vista e decisões comuns que respeitem e promovam os direitos humanos, a consciência socioambiental e o consumo responsável em âmbito local, regional e global, com posicionamento ético em relação ao cuidado de si mesmo, dos outros e do planeta.

8. Conhecer-se, apreciar-se e cuidar de sua saúde física e emocional, compreendendo-se na diversidade humana e reconhecendo suas emoções e a dos outros, com autocrítica e capacidade para lidar com elas.

9. Exercitar a empatia, o diálogo, a resolução de conflitos e a cooperação, fazendo-se respeitar e promovendo o respeito ao outro e aos direitos humanos, com acolhimento e valorização da diversidade de indivíduos e de grupos sociais, seus saberes, identidades, culturas e potencialidades, sem preconceitos de qualquer natureza.

10. Agir pessoal e coletivamente com autonomia, responsabilidade, flexibilidade, resiliência e determinação, tomando decisões com base em princípios éticos, 
democráticos, inclusivos, sustentáveis e solidários (BRASIL, BNCC, 2017, pp. 9-10)

É notório que muitas dessas competências, apesar de adotarem uma narrativa efetivamente interdisciplinar, não serão concretizadas por longos anos, por conta de razões sociais, políticas e econômicas das mais diversas e das mais adversas aqui existentes. Outros ordenamentos que seguem uma narrativa similar padecem dos mesmos problemas. Mesmo os educadores, de modo geral, ao tratarem de algumas questões pertinentes a um padrão epistemológico na educação voltado para a interdisciplinaridade tem se distanciado dela, mesmo se considerarmos uma ação mais voltada a adoção de uma concepção curricular a-histórica relatada por Comes da Silva.

\section{O estudo da cultura na Educação Brasileira e seus diferentes posicionamentos}

Uma questão que tem sido marcadamente estudada pelos educadores em geral e referendada nos ordenamentos de ensino está centrado no repasse da cultura erudita e da cultura popular no contexto escolar. Este repasse propaga uma tendência hierarquizante, dicotomizada e polarizada de ensino que privilegia mais intensamente a transmissão de padrões ditados pela cultura erudita, minimizando aspectos importantes contidos na cultura popular e que, na melhor das hipóteses, não deveriam ser excluídos, mas sim, veiculadas de forma integrada, tendo em vista a interligação de uma cultura com a outra. É nesse ponto que vamos nos deter, mesmo tendo conhecimento da gama infinita de questionamentos que deveriam ser avaliados um a um.

As culturas, em permanente estado de mutação e mobilidade, devem ser entendidas e avaliadas nas suas múltiplas articulações. Assim dito, a cultura erudita e a cultura popular não são conceitos excludentes. Pensar a cultura popular em contraposição à chamada "cultura erudita" é não pensar o quanto as manifestações culturais são dependentes umas das outras e em que medida elas interagem.

De certa maneira essa divisão encontra alicerce na prática habitual de se dissociar o "fazer" do "saber", uma vez que essa prática 
atribui ao popular mais a ideia de fazer do que a de pensar. Trata-se de procedimento inadequado, em razão da comprovada interdependência que existe entre os diversos campos de conhecimento. Quase sempre, a cultura erudita está relacionada à ideia de preservação de uma prática cultural que não pode e não deve sofrer as intempéries do tempo, diversamente do que é pensado para a cultura popular.

Hoje, com a internacionalização do capital e dos sistemas de comunicação e informação, algumas produções culturais regionais parecem ter sido mais valorizadas. Isso, de certa maneira, faz pensar que há um comportamento social e intencional de se elevar a cultura popular ao mesmo patamar da chamada "cultura erudita", ou pelo menos, consubstanciá-la como algo formalizado graças a uma tradição solidificada no tempo. Contudo, uma tendência contrapõese quando estruturas capitalistas objetivam conferir à cultura popular sentido semelhante àquele atribuido à noção de indústria cultural, com $o$ intuito de diminuir sua força, considerando-se que a indústria cultural é destituida de um sentido mais crítico e reflexivo e está mais comprometida com as tendências veiculadas pelo mercado. Sob essa perspectiva, parece que a indústria cultural poderia de alguma maneira abarcar de forma nociva os contextos populares, manipulando-os de acordo com as necessidades dos mercados.

Contudo, a cultura popular traz em si mecanismos de defesa bem mais eficazes e complexos do que aqueles que norteiam a indústria cultural, que interagindo às situações, preservam sua autenticidade. Essas culturas se rearticulam, recompõem seus códigos e linguagens e se apropriam de novos elementos, mantendo sua dinamicidade sem esvaziar seus conteúdos.

Para Antonio Augusto Arantes, pensar a cultura popular como sinônimo de "tradição" é desconhecer as sucessivas modificações pelas quais necessariamente passaram os objetos, concepções e práticas culturais, pressupondo que ela seja passivel de cristalização, permanecendo imutável no tempo a despeito das mudanças que ocorrem na sociedade, ou quando muito, que ela esteja em eterno "desaparecimento". Ele vê a cultura como um processo dinâmico:

[...] transformações (positivas) ocorrem, mesmo quando intencionalmente se visa congelar o tradicional para impedir a sua "deterioração". É possível preservar os objetos,

\section{5}

REV. TULHA, RIBEIRÃO PRETO, v. 6, n. 2, pp. 90- 11 18, jul.-dez. 2020 
os gestos, as palavras, os movimentos, as características plásticas exteriores, mas não se consegue evitar a mudança de significado que ocorre no momento em que se altera o contexto em que os eventos culturais são produzidos (ARANTES, 1981, pp. 21-22)

Arantes vê a cultura popular resistente em dois sentidos. Em primeiro lugar, porque interpretando diferentemente o mesmo conjunto de símbolos, reproduzem-se metaforicamente as diferenças que realmente existem e continuam sendo objetivamente reproduzidas. Em um segundo momento, porque, a partir da reinterpretação de um material simbólico, recriam-se formas de sociabilidade, modos de organização e se expressam interesses que podem se contrapor aos padrões e interesses dominantes. Sob essa perspectiva, os eventos culturais não são "coisas", mas produtos significantes da atividade social de homens determinados, cujas condições históricas de produção, reprodução e transformação devem ser desvendadas.

Arantes entende que os eventos culturais se articulam na esfera do político, no sentido mais amplo do termo, ou seja, no espaço das relações entre grupos e segmentos sociais. Dessa maneira, o estudo das manifestações culturais deve detectar os constrangimentos que limitam a sua articulação efetiva e a sua transgressão e superação em situações concretas (ibid, pp. 50-51).

Contrapondo-se à cultura de massa, que tem uma tendência homogeneizadora sobre um corpo social, mas, na verdade, é diferenciada, a cultura popular possui em suas raízes, uma heterogeneidade real resistente a esses mecanismos. Essa explanação evidencia a importância de se analisar os fenômenos culturais sob bases e mediações dialéticas.

A pesquisadora Lúcia Santaella considera importante resgatar os alicerces materiais e concretos dos fenômenos culturais em sua especificidade e vê a dimensão cultural como uma estrutura complexa de práticas diferenciadas e específicas:

Não se trata aqui, de impor a visão da dimensão cultural como independente dos condicionamentos econômicos, pois que isso seria incorrer no idealismo de se conceber o econômico como corpo material, regido pela política, e a

\section{6}

REV. TULHA, RIBEIRÃO PRETO, v. 6, n. 2, pp. 90- 11 , jul.-dez. 2020 
cultura como expressão do espiritual, ou como expressão das questões da alma coletiva que não se maculam nas intempéries do corpo (SANTAELLA, 1990, pp. 34-35).

Ela entende que os fenômenos reais, concretos, sejam eles culturais, políticos ou econômicos são síntese de múltiplas determinações. Não se apresentam como dados já prontos, transparentes, inequivocos. Eles precisam ser decifrados, desvendados. Só a análise rigorosa das condições reais de existência material e social dos agentes coletivos em situações concretas, podem nortear as opções possiveis de intervenção transformadora dessas condições. Um outro tipo de análise não é capaz de projetar a especificidade criativa da produção artística $e$ as mediações da arte em relação a outras produções culturais. Ela confunde a dimensão política e cultural dessas produções, perdendose assim os meios de intelegibilidade dos modos como essas dimensões sociais se determinam mutuamente e sobredeterminam o econômico (ibid, pp. 38/4 l)

Assim exposto, o estudo da cultura popular, quer na Educação, quer na pesquisa, propiciará a formação de mecanismos eficientes para a valorização das produções artísticas e científicas nacionais, sem atribuir-lhes contextos políticos partidaristas, tão dependentes de uma política econômica. A proposta poderá conferir à educação uma unificação de seus conteúdos de análise e à produção artística, maior valorização de sua dimensão estética e social. Esses critérios determinarão para a cultura brasileira e para a produção artística, uma participação mais efetiva no processo de internacionalização cultural.

O texto de Maria de Lourdes Rangel Tura (2005) traz uma discussão sobre a dinâmica da interação de diferentes padrões e lógicas culturais que se comunicam no interior do espaço escolar, a partir da leitura dos estudos históricos culturais de Carlo Ginzburg. Interessa a esta autora destacar as permutações entre a cultura erudita e a cultura popular e as formas de comunicação entre o clássico e a vulgata, que para Ginzburg foi definida pelo termo circularidade entre culturas:

[...] (circularidade entre culturas) explica o relacionamento circular feito de influencias recíprocas (p.13) entre as culturas dominantes e dominadas e que se movia tanto de 
cima para baixo quanto de baixo para cima. Esta análise se opõe ao conceito de autonomia e continuidade de qualquer cultura (TURA, 2005, p. 155).

Tura relata que a dificuldade em se estudar a cultura popular que basicamente se instituiu pela tradição oral e por seus poucos produtos literários (almanaques, canções e receitas, narrativa da literatura de cordel, entre outras) parecem ser reflexo de um saber simplório ou simplificado imposto às classes populares. Nesse sentido a noção de circularidade entre culturas, presente nos estudos de Ginzburg, estabelece uma modalidade fundada na inter-relação e na intertextualidade das culturas e subentende movimentos ascendente e descendentes que se processam no interior de uma hierarquia de poderes:

Nesse movimento se instituem aproximações e nexos, adaptações e deslocamentos, que unem temas tratados em tempos diferentes, perspectivas diversas, contexto antagônicos e que se ampliam em um diálogo, que emerge de um fluxo de rupturas e descontinuidades de relações lógicas (TUMA, 2005, p. 155).

Ginzburg realizou seus estudos no caldeamento de influências, trocas e confrontes entre culturas que se comunicam e se comunicaram. Foi na leitura de textos literários, das lendas, da narração de festas populares e outras tantas publicações, que ele encontrou as bases para a compreensão da forma como se processa a interação entre culturas (TURA, 2005, p. 151). Seus questionamentos estiveram focados em compreender se a cultura popular existia ou se ela não era apenas um simulacro de baixa extração da cultura dominante. Conforme relatado por Tura:

São as inúmeras faces da produção discursiva e cultural de diversos povos e tradições religiosas, que parecem encadear-se em nexos incomensuráveis, em desdobramento políticos, em temas filosóficos, em práticas consagradas, em ritos, advinhas, provérbios, réplicas da oratória clássica (TUMA, 2005, p. 156). 
Se pensarmos mais atentamente na função e sentido pedagógico e político do currículo escolar, deparamo-nos com a ideia central alicerçada em suas bases. Trata-se de uma seleção organizada de conteúdos que necessitam ser aprendidos e que regularão a prática didática a ser trabalhada nas diversas etapas de ensino. Ele não só organiza e unifica o que deve ser ensinado, como também delimita os conteúdos que serão abordados em cada disciplina, evitandose uma ação pedagógica caótica, repetitiva e desorganizada por parte dos docentes. Essa finalidade didática a ele atribuída, se mal direcionado tende a engessar o processo de ensino/aprendizagem dos cursos em geral. Desta maneira, cada uma das instituições deve rever continuadamente as ações pedagógicas que as envolvem, verificar em que medida elas se integram às demais áreas de conhecimento e em que momento tendências inoperantes devem ser abolidas.

A pedagoga Inês Dussel, ao avaliar a importância do currículo escolar na atualidade , relata que essa valorização é consequência das transformações pelas quais vêm passando as sociedades atuais, principalmente se considerarmos o quanto os fenômenos de globalização econômica, mundialização da cultura e redução das distâncias espaçotemporais tem convivido com a substituição da ideia de nação, por identidades locais, muito mais plurais, configurando-se dessa forma em uma área interdisciplinar híbrida que concilia teoria, pesquisa e prática institucional. Pensar o currículo em termos de hibridação contribui para analisar a complexidade dos processos de produção culturais, políticos e sociais que o configuram, introduzindo novas ideias em um campo cujas perguntas foram, muitas vezes, pobres teórica e tecnicamente. A hibridação não só se refere a combinações particulares de questões díspares, como nos recorda que não há formas puras e intrinsecamente coerentes, sejam elas identitárias, materiais, tecnológicas, entre outras, ainda que essa mescla não seja intencional (DUSSEL, 2005, p. 57 e 65).

A autora Marisa V. Costa, debruçando-se sobre a mesma temática, relata que é na cultura que se dá a luta pela significação, na qual os grupos subordinados tentam resistir à imposição de significados que sustentam os interesses dos grupos dominantes. Nesse contexto, os textos culturais precisam ser estudados no ambiente escolar, pois são um produto social relevante, onde o significado é negociado e

3 Na discussão que se segue sobre currículo foram referendados, entre outros, os textos de autores publicados no livro Currículo: Debates Contemporâneos, organizado por Alice Casimiro Lopes e Elizabeth Macedo, 2005. São Paulo: Editora Cortez. 
fixado e as diferenças e a identidade também são produzidas e fixadas (COSTA, 2005, p. 138). Para esta autora todos os locais da cultura em que o poder se organiza e se exercita, como programas de TV, filmes, jornais, revistas, brinquedos, catálogos, propagandas, anúncios, videogames, livros, esportes, shopping centers, entre tantos outros, são espaços que educam, praticando pedagogias culturais que moldam nossa conduta. As pedagogias culturais vão formatando a nossa identidade, na medida em que envolvem nosso desejo, capturam nossa imaginação e vão construindo a nossa consciência. Isso significa que há pedagogias culturais e currículos culturais em andamento dentro e fora das instituições educacionais, estruturados de acordo com as forças que regem a dinâmica comercial, política e cultural predominante no mundo contemporâneo.

Esse modo de pensar ajuda a entender porque as questões culturais ocupam cada vez mais o centro dos debates sobre as políticas públicas e em que bases elas devem ser ensinadas. Os estudos culturais parecem ser intensamente permeáveis às mudanças históricas, à diversidade de enfases problemáticas em diferentes momentos e geografias, e têm se caracterizado pelo debate amplo, pela divergência e pela intervenção, cabendo às escolas parte dessa compreensão (COSTA, 2005, pp. 144 e 145).

Examinar e discutir esses textos culturais, dentre tantas outras possibilidades, é uma das formas de participarmos politicamente de uma sociedade menos discriminadora e excludente. Os estudos culturais e sua multiplicidade de possiblidades analíticas são, certamente, uma das chances que temos de não nos conformarmos em ser meros espectadores de conflitos étnicos, raciais e religiosos que assolam algumas regiões, povos e culturas do mundo, mas que também acontecem ao nosso lado, diante dos nossos olhos.

Costa entende que a análise e a discussão dessas questões deveriam permear os currículos escolares em todos os graus do ensino e em todas as modalidades. Diante desse relato, não me parece adequado ignorar essa realidade na educação básica, nos cursos superiores de música e nos cursos de pós-graduação.

Para a pedagoga Maria de Lourdes Rangel Tuna (2005) a escola, de modo geral, é um local privilegiado para a troca de ideias, 
de encontros, de interação entre gerações, legitimação de práticas sociais, de articulação entre diversos padrões e modelos cognitivos:

Isso se deve à sua ação sistemática de transmissão de conhecimentos, competências e disposições socialmente reguladas à população de crianças e jovens de uma específica organização social. Esse é o lugar onde se podem participar efetivamente de uma educação mais interligada com os problemas e dilemas do mundo contemporâneo em que vivemos [..] a intertextualidade que permeia o confronto de posições, sentidos e estilos de vida no ambiente pedagógico permite entende-los como um importante espaço de circularidade entre culturas e avaliar as complexas articulações produzidas entre os diversos discursos e redes simbólicas que convivem em seu interior e as determinações e proposições de um currículo escolar, rigidamente formalizado, hierarquizado e seletivo (TUNA, 2005, p. 156/7).

Quando dirigimos nossos olhos para educação básica, vamos verificar que tanto as crianças como os jovens ali inseridos trazem para a sala de aula um conhecimento já produzido anteriormente e um conhecimento artístico informal, oriundo das práticas familiares, socioculturais e midiáticas. Esse conhecimento traduz-se em um espaço social básico, no qual a aprendizagem informal já se realizou, revela os hábitos de escuta da criança e dos jovens, os seus gostos musicais, seus gostos artísticos e suas preferências. Cabe aos professores de artes, verificar em que medida essa bagagem musical informal pode ou não condicionar a postura desses alunos em relação às práticas e projetos artísticos voltados para esse nivel de ensino. Sob essa perspectiva é importante averiguar que espaço será destinado para o aprendizado das artes e qual o peso que deve ser destinado ao aprendizado obtido anteriormente nessa nova estrutura. Essa reflexão é de extrema complexidade, pois envolve um fazer pedagógico que necessita, por conta dos ordenamentos, integrar todas as linguagens artísticas, trabalhar com padrões socioculturais diversos e, que em função do parco espaço destinado ao ensino das artes, prioriza o repasse de atividades artísticas extracurriculares.

Partindo desses pressupostos, é importante ao professor de artes na educação básica, conhecer e valorizar o conhecimento informal

\section{1}

REV. TULHA, RIBEIRÃO PRETO, v. 6, n. 2, pp. 90- 11 , jul.-dez. 2020 
trazido por esses alunos, não só para usá-lo como estratégia motivadora do ensino artístico, mas também, para entendê-lo como fenômeno social humano. A partir disso, ele poderá ampliar a bagagem artística desses alunos, não porque esse conhecimento cotidiano deva ser negado ou considerado "inferior", mas porque ele é limitado em sua essência. Essa medida permitirá que esses alunos possam apreciar as mais diversas produções artísticas existentes, sejam elas regionais, nacionais ou internacionais; sejam elas produções voltadas para a cultura erudita, popular ou folclórica, ou até mesmo para as produções hibridas.

Sob essa perspectiva, o relato da pedagoga Carlinda Leite é providencial ao admitir que não é possivel pensar a educação sem, simultaneamente, pensar a cultura e as relações existentes entre ambas. A educação supõe não apenas a reprodução do saber e das culturas, mas também a produção de novos saberes e de novas expressões culturais: "é nesse confronto entre um papel mais reprodutivo ou mais produtivo que se tem debatido o conteúdo cultural escolar" (LEITE, 2001, p. 46).

A pedagoga Maria de Lourdes Rangel Tura (2005), por sua vez, aponta para a dificuldade que a educação tem em administrar os avanços socioculturais, científicos e tecnológicos cada vez mais presentes no mundo contemporâneo; dificuldade em administrar o cotidiano cultural trazido pelo corpo discente, bem como adequar a prática docente de maneira a ser condizente com aquilo que está descrito nos ordenamentos pedagógicos. Para tanto apresenta um testemunho de V. M. Candau exposto no livro Reinventar a Escola (2000):

A dinâmica cristalizada na cultura escolar apresenta uma enorme dificuldade de incorporar os avanços do desenvolvimento científico e tecnológico, as diferentes formas de aquisição de conhecimentos, as diversas linguagens e expressões culturais e as novas sensibilidades presentes de modo especial nas novas gerações e nos diferentes grupos culturais [..] Chama a atenção quando se convive com o cotidiano de diferentes escolas, como são homogêneos os rituais, os símbolos, as comemorações de datas cívicas, as festas, as expressões culturais, etc (CANDAU, 2000, 53-54, apud TURA, 2005, p. 168).

\section{2}


Tura, em sua explanação, retoma o sábio entendimento de Gimeno Sacristán ( 1995, p. 88) com relação a cultura escolar que, para este pedagogo, deveria estar necessariamente presente no trabalho docente e no contexto escolar:

Do ponto de vista pedagógico, o importante não são as declarações ou os desejos sobre aquilo que queremos introduzir nos currículos, mas a experiência que é vivida pelo aluno. Quando entendemos a cultura não como os conteúdos-objeto a serem assimilados, mas como o jogo de intercâmbios e interações que são estabelecidos no diálogo da transmissão-assimilação, convém estarmos conscientes de que em toda experiência de aquisição se entrecruzam crenças, aptidões, valores, atitudes e comportamentos, porque são sujeitos reais que thes dão significados, a partir de suas vivências como pessoas (SACRISTÁN, 1995, p. 88, apud TURA, 2005, p. 169)

A fala de Gimeno Sacristán, citada por Tuna, reporta-se a necessidade de se entender a cultura escolar como um jogo de interesses e interações estabelecidos no diálogo transmissão/assimilação de conteúdos disciplinares, já que os sujeitos educacionais devem ser vistos como sujeitos culturais, que irão conferir significado e sentido aos conhecimentos escolares obtidos e isso só se realiza em um processo de interação entre as culturas que produz outro discurso, muitas vezes, estranho aos próprios professores.

Pautada em Gimeno Sacristán e no conceito de circularidade cultural proposto por Ginzburg, Tuna vê como necessário que as escolas, convivam com um aluno que ao mesmo tempo é criativo, híbrido, reativo e construtor de significados. Esse discurso, apesar de ter sido pontuado pelos ordenamentos relativos ao ensino na educação básica brasileiro, ainda parece um pouco distante de acontecer no que diz respeito ao ensino musical, considerando-se a dicotomia e fragmentação das propostas curriculares que acercam esse campo de conhecimento, bem como a falta de continuidade desse aprendizado na educação infantil, fundamental e média. Seria necessário que tanto as instituições de ensino voltadas para a educação básica como seus docentes estivessem atentos para reformular, conservar ou implantar medidas e ações curriculares voltadas para o ensino musical mais condizentes com a realidade sociocultural de nosso território e com as

\section{3}

REV. TULHA, RIBEIRÃO PRETO, v. 6, n. 2, pp. 90- 1 18, jul.-dez. 2020 
intenções pedagógicas apontadas pelos pesquisadores e estudiosos da Educação. Nesse sentido, a compreensão da produção musical contemporânea sob essa perspectiva torna-se fundamental.

\section{A produção musical contemporânea}

Ao nos determos na produção musical erudita contemporânea, o musicólogo Enrico Fubini (200l) traz um dado importante a ser considerado. Ele descreve a indeterminação e a estrutura que tem norteado a vanguarda musical. A evolução veloz dos meios técnicos, da linguagem e das atitudes assumidas pelos compositores contemporâneos, torna difícil aos estudiosos estabelecer escalas de valores e guias para a produção musical atual. Contudo, a ele parece desnecessário estabelecer uma escala de valores entre as várias alternativas composicionais existentes, pontuar qual o seu valor ou desvalor estético, ou mesmo pensar a música erudita como uma linguagem expressiva ou como uma ordem formal, já que a música nova não reconhece nenhuma tradição, ela se propõe a ser intranscedente e objetiva destruir o sentido que até então the fora conferido (FUBINI, 2001, p. 13 1/2).

Os músicos e artista atuais sentem uma necessidade de justificar no plano crítico, técnico e filosófico seu modo de compor. Qualquer poética pode ser válida e renegar a estrutura até então ofertada. som na atualidade se oferece sem uma distinção do que é som do que é ruído e como tal deve ser explorado. Trata-se então de uma investigação experimental, conferindo a produção artístico-musical um sentido mais científico de criação:

[...] la vanguardia se propone cumplir con una doble tarea: por una parte, se impone a sí misma la ruptura sistemática con todo nexo lingüístico tradicional, gracias al empleo de ruidos, de sonidos electrónicos, de instrumentos tradicionales usados fuera de su contexto, lo que se consigue por obra del escándalo intencionado, de la acción o el gesto provocador y profanador; por outra parte, aspira a la construcción de un nuevo mundo sonoro, llevando adelante el programa señalado por Webern, consistente en 
la serialización integral de todos los posibles parámetros sonoros (FUBINI, 2001, p. 14 I)

Como exemplo Fubini cita o compositor J. Cage, no qual a negação da estrutura se faz de forma radical. Em sua obra observa-se a carência de expressão, a falta de vontade criadora, a ausência de toda subjetividade e principalmente a imediatez na proposta criativa. No lugar de qualquer tipo de organização, este compositor coloca o casual como objetivo composicional, ou seja, um jogo composicional sem regras. A vanguarda se manifesta como um processo composicional que nega qualquer concepção linguística da música e a abolição de todo gênero de hierarquização. Na verdade, na música de vanguarda o interesse composicional reside em produzir uma música absoluta e sem história. A vanguarda não pretende fazer uma música que sirva para se comunicar, ao contrário, ela pretende não se comunicar, nem se articular com a tradição (FUBINI, 2001).

Esse relato aponta para o isolamento epistemológico presente na produção musical contemporânea, que se opõe a se subjugar aos contextos culturais propagados na sociedade atual e que de certa forma manifestam uma fazer musical fragmentado e hiperespecializado, na contramão de um padrão cultural híbrido presente em muitas das produções artísticas contemporâneas.

Por sua vez, o musicólogo John Sloboda, ao relatar a ligação da cultura com o pensamento musical, avalia os fatores culturais e sociais que ajudam a dar conta das vastas diferenças que existem entre as culturas musicais do mundo, o que faz intuir a profunda interrelação cultural que tem se estabelecido no mundo contemporâneo:

As culturas contemporâneas podem ser dispostas ao longo de um continuum que vai desde as culturas em que não há letramento até aquelas em que o letramento permeia todos os aspectos da atividade social. Há muitas culturas "semiletradas", em que o letramento existe em classe ou em situações restritas, e isso tem efeitos diretos sobre os membros orais da cultura. Até mesmo nas culturas predominantemente letradas, tais como a nossa, pode haver indivíduos que não são letrados, mas que acabam realizando atividades de que se baseiam, direta ou indiretamente, no letramento de outros. Por outro lado, os indivíduos que são plenamente

\section{5}

REV. TULHA, RIBEIRÃO PRETO, v. 6, n. 2, pp. 90- 11 , jul.-dez. 2020 
letrados podem, ao mesmo tempo, ter áreas de atividades significativas que são essencialmente orais. Muitos ocidentais são linguisticamente letrados e musicalmente orais. Algumas pessoas musicalmente letradas mantêm áreas de atividades, como o jazz e a música folclórica, que são essencialmente orais. Portanto, a distinção letrado/oral não é tão clara culturalmente falando (SLOBODA, 2008, p. 322)

$\bigcirc$ discurso aqui trazido entre a importância de agregarmos nos contextos escolares e no currículo a cultura popular e a cultura erudita demonstra o quanto afastados ainda estamos de referendar uma matriz curricular interdisciplinar nas diversas modalidades de ensino do país, principalmente quando nos reportamos ao ensino musical. Muito mais poderia ser dito quanto a utilização de um currículo interdisciplinar no contexto educacional brasileira, mas a fala de Gomes da Silva pareceu-me bastante completa e instigante para começarmos a refletir em uma constante remodelação curricular deste ensino, para um retorno do pensamento holístico empregado na Crécia Antiga ou a produção de um novo padrão epistemológico a ser adotado que teria como prioridade beneficiar o homem contemporâneo e a sociedade como um todo e a música como uma linguagem de importância capital ao desenvolvimento humano.

\section{Referências}

ARANTES, Antonio Augusto. O que é cultura popular. 1981.14 ed. São Paulo: Brasiliense, 1990.

COSTA, Marisa Vorraber. Poder, discurso e política cultural: contribuições dos estudos culturais ao campo do currículo. In: LOPES, Alice Casimiro \& MACEDO, Elizabeth (orgs). Currículo: debates contemporâneos, $2^{\natural}$ edição, São Paulo: Cortez Editora, 2005.

DUSSEL, Inés. $\bigcirc$ currículo híbrido: domesticação ou pluralização das diferenças? In: LOPES, Alice Casimiro \& MACEDO, Elizabeth (orgs). Currículo: debates contemporâneos, $2^{a}$ edição, São Paulo: Cortez Editora, 2005. 
FUBINI, Enrico. Música y linguaje en la estética contemporánea. Espanha: Alianza Música, 2001.

COMES DA SILVA, Maria de Fátima. Para uma ressignificação da interdisciplinaridade na gestão dos currículos em Portugal e no Brasil. Portugal - Coimbra: Fundação Calouste Culbenkian, 2009.

LEITE, Carlinda. $\bigcirc$ lugar da escola e do currículo na construção de uma educação intercultural. In: CANEN, Ana e MOREIRA, Antonio Flavio Barbosa (orgs). Enfases e omissões no currículo. Campinas, SP: Papirus, 2001 , pp. 45-64.

LENOIR, Yves. Didática e interdisciplinaridade: uma complementaridade necessária e controlável. In. FAZENDA, Ivani C. Arantes (org). Didática e Interdisciplinaridade. Campinas, SP: Papirus, pp. 45-75, 1998.

SANTAELLA, Lúcia. (Arte) \& (cultura): equívocos do elitismo. 2. ed. São Paulo: Cortez, 1990.

SILVA, Maria de Fátima Comes da. Para uma ressignificação da interdisciplinaridade na gestão dos currículos em Portugal e no Brasil. Portugal Edição Fundação Calouste Gulbenkian, Fundação para a Ciência e Tecnologia. 2009.

SLOBODA, John A. A mente musical: a psicologia cognitiva da música. Tradução de Beatriz ilari e Rodolfo llari. Londrina: EDUEL, 2008.

TURA, Maria de Lourdes Rangel. Conhecimentos escolares e a circularidade entre culturas. In. In: LOPES, Alice Casimiro \& MACEDO, Elizabeth (orgs). Currículo: debates contemporâneos, $2^{\circ}$ edição, São Paulo: Cortez Editora, 2005, pp. 150 a 173. 


\section{Sobre a autora}

Sonia Regina Albano de Lima. Doutorado em Comunicação e Semiótica-Artes (PUC/SP, 1999); pós-doutorado em interdisciplinaridade e educação pelo Grupo de Estudos e Pesquisa em Interdisciplinaridade da PUC-SP (CEPI-PUC/SP), sob a orientação da Prof. Dr. Ivani C. A. Fazenda; pós-doutorado em Música no IA-UNESP (2015), sob supervisão da Prof. D. Yara Caznók, pós-graduação lato sensu em práticas instrumentais e música de câmara ( Faculdade de Música Carlos Comes - FMCG); especialização em interpretação musical e música de câmara com o Prof. Walter Bianchi ( FMCG); bacharelado em instrumento - piano (FMCG, 1982); bacharelado em direito (USP, 1973); licenciatura curta em educação musical e habilitação para o ensino de piano (Instituto Musical de São Paulo, 1967). Estudou piano e música de câmara com os professores Martin Braunwieser, Sonia Muniz, Roberto Sabbag e Walter Bianchi. Participou de cursos de extensão com intérpretes nacionais e internacionais, entre eles destacam-se: Bruno Seidholfer, Camargo Guarnieri, Rosalyn Tureck, Sérgio Magnani e Homero Magalhães. Foi professora de piano da Escola Municipal de Música (EMM) de 1975 a 1999. Na FMCG foi professora de música de câmara e piano (1983 a 1993); vice-diretora (1985 a 1999); diretora executiva (1999 a 2010); coordenadora pedagógica dos cursos de graduação (canto, instrumento, composição e regência) e pós-graduação lato sensu em educação musical e música (1998 a 2009). Foi professora pesquisadora da UNIABC de 2010 a 2012 para a implantação do Mestrado Profissional em Educação; bolsista coordenadora de pesquisa da FUNADESP (2012). É professora do Programa de Mestrado e Doutorado em Música do IA-UNESP desde 2005. Foi diretora e coordenadora artística da Escola de Música de São Paulo de 2013 a 2014 . É pesquisadora junto ao CEPI-PUC/SP e líder de pesquisa do Grupo de Pesquisa em Educação Musical do IAUNESP (C-PEM- IA-UNESP). Foi colaboradora no Projeto Pensar e Fazer Arte da PUC/SP sob a organização do Prof. Dr. Cláudio Picollo. Autora e organizadora de livros, coletâneas e textos de revistas científicas voltadas para a interdisciplinaridade, performance e educação musical. Foi Presidente da Associação Nacional de Pesquisa e Pós-Graduação em Música de 2015 a 2019. 